\title{
Doxorubicin/Prednisone/Vincristine Regimen
}

National Cancer Institute

\section{Source}

National Cancer Institute. Doxorubicin/Prednisone/Vincristine Regimen. NCI Thesaurus.

Code C9647.

A chemotherapy regimen consisting of doxorubicin, prednisone, and vincristine that may be used in the treatment of Hodgkin lymphoma (HL). 